Research Journal of Applied Sciences, Engineering and Technology 6(1): 102-106, 2013

DOI:10.19026/rjaset.6.4042

ISSN: 2040-7459; e-ISSN: 2040-7467

(C) 2013 Maxwell Scientific Organization Corp.

$\begin{array}{lll}\text { Submitted: October 22, } 2012 & \text { Accepted: November 19, } 2012 & \text { Published: June 05, } 2013\end{array}$

\title{
Research Article Relationship between Bridge Natural Frequencies and Foundation Scour Depth Based on IITD Method
}

\author{
${ }^{1,3}$ Xiaozhong Zhang, ${ }^{2}$ Yaoyong Chen and ${ }^{1}$ Wenjuan Yao \\ ${ }^{1}$ Department of Civil Engineering, Shanghai University, Shanghai 200072, China \\ ${ }^{2}$ Wenzhou Vocational College of Science and Technology, Zhejiang Province 325000, China \\ ${ }^{3}$ School of Architecture and Civil Engineering, Quzhou University, Quzhou 324000, China
}

\begin{abstract}
In this study, we want to find out the relationship between the bridge natural frequency and the bridge foundation scour depth. The Improved Ibrahim Time Domain (IITD) method and the finite element models are applied to solve the problem. Firstly, IITD method was described in detail for using to solve the natural frequency at ambient excitation. Secondly, the detailed steps of expiring the relationship between bridge natural frequencies and foundation scour depth are explained using IITD method and finite element techniques. Finally, the natural frequency of Qujiang Bridge is calculated at different scour depth. The detailed analysis of the natural frequency of the bridge with the variation of scour depth can able to explore the impact of bridge scour damage for structural safe operation. The results of calculated showed the IITD method that considered the ambient excitation is much more powerful and accurate than Irahim Time Domain (ITD) method. So IITD can apply to bridge scour damage detection with finite element techniques. This study laid the foundation for the bridge scour identification.
\end{abstract}

Keywords: Ambient excitation, bridge natural frequencies, finite element techniques, foundation scour depth, IITD method, relationship

\section{INTRODUCTION}

The piers of cross-river Bridge laid above the river, the elevation of the original riverbed bottom have a sharp decline in the force of flood scour, lead to the load acting on the piers and pile foundation changed greatly with the original design. Therefore, the resisting risk of the piers and pile foundation has reduced greatly. Eventually lead to bridge a serious security risk, this phenomenon has become increasingly aroused the attention of bridge engineering sector. The investigation finding of bridge collapse occurred in the domestic and international all have shown that scour is the main reason for the collapse of a bridge in service ( $\mathrm{Ji}$ and $\mathrm{Fu}$, 2010; Wardhaha and Hadripriono, 2003; Robertson et al., 2007; De Falco and Mele, 2002). In order to avoid the collapse of the bridge caused by flood, not only the health status of the bridge needed to be detected and evaluated in time, but also the scour damage of the bridge needed to be detected and estimated quickly, so effective measures can be taken to ensure the safe of the bridge in service. However, it is difficult to measure the situation of the bridge foundation scour directly, because the foundation of across Rivers Bridge or coastal bridge all is below the surface of the water. Application of underwater detection equipment testing scour condition, not only the cost of testing is expensive, time consuming, require specialized technical training, but also detection accuracy of the measurement results can not satisfy requirements because the environmental impact of floods and other outside interference (Darghi, 1990; Melville and Raudkivi, 1996; Mattin-Vide, 1998; Dey, 1999). And in the growth of the flood, the increase in the speed and height of the water, resulting in welcoming the water surface near the pier was washed into the pit. The flood fall, the water velocity decreases, the water partially particles precipitate fill the scour hole. These sediments filled the absence compaction cannot provide good constraints for piers or piles, but the application of underwater detection equipment cannot fill some of the detected, so the application of underwater detection equipment to scour detection does not directly reflect the bridge the true erosion damage. Based on this, the domestic and international scholars in the last twenty years, launched a series of theoretical and experimental research for scour damage recognition of bridge without the underwater detection equipment (Oliveto and Harger, 2002; Coleman, 2005; Harger and Unger, 2010; Lu et al., 2011; Karami et al., 2012).

In summary, it is necessary to build a bridge monitor system to judge the state of the bridge. The main purpose of this study is to find out the relationship between the bridge natural frequency and the bridge foundation scour depth. To analyze the association, The IITD method and the finite element models are created.

Corresponding Author: Wenjuan Yao, Department of Civil Engineering, Shanghai University, Shanghai 200072, China

This work is licensed under a Creative Commons Attribution 4.0 International License (URL: http://creativecommons.org/licenses/by/4.0/). 
The bridge model established in this study only considers the foundation difference. That is, the superstructure of the bridge is not changed. The formations of the piles include several different depths. Since the numerical procedure of the analysis will take a long time, the bridge model should be checked carefully before running the analysis. The IITD method considered the ambient excitation; it was improved based on Irahim Time Domain (ITD) method. After the finite element analysis, the frequency-scour depth relationship can be found based on IITD method.

\section{METHODOLOGY}

Improved Ibrahim Time Domain (IITD) method: To discover the natural frequency analysis with the bridgesoil interaction, the dynamic problem is considered. According to random decrement method, a dynamic equation of motion is expressed as follows:

$$
M \ddot{X}+C \dot{X}+K X=0
$$

where,

$\mathrm{M}, \mathrm{C}, \mathrm{K}$ : Mass, damping and stiffness respectively

$\ddot{X}, \dot{X}, X$ : The acceleration, velocity and displacement respectively

Neglecting the damping the Eq. (1) can be rewritten as:

$$
M \ddot{x}(t)+K x(t)=0
$$

The solution of the Eq. (2) can be expressed as $\mathrm{x}(\mathrm{t})$ $=\varnothing \mathrm{e}^{\lambda t}$. Therefore, the Eq. (2) can be changed to the following equation:

$$
\left(K-\omega^{2} M\right) \phi=0
$$

Equation (3) is an eigenvalue problem; which $\square \square$ $\omega^{2}$ represents the natural frequency of the system and $\varnothing$ represents the modal shape of the system.

To consider the influence of noise and multiple degrees of freedom, the Eq. (3) of the structure can be expressed as:

$$
\left(X(t)=\sum_{r=1}^{2 n} \phi_{r} e^{\lambda_{r} t}+N(t)\right.
$$

where,

$\emptyset_{\mathrm{r}}$ : The $\mathrm{r}^{\text {th }}$ modal shape of the system

$\lambda_{r}$ : The eigenvalue of $\mathrm{r}^{\text {th }}$ modal of the vibration system

$\mathrm{N}$ : Noise pollution of measurement

Located in the 1 at single excitation conditions, the free response of the structure matrix $\mathrm{X}$ and $\hat{X}$ consists of the following elements:

$$
x_{i j}=x_{i}\left(t_{j}\right)
$$

$$
x_{i j}=x_{i}\left(t_{j}+\Delta t\right)
$$

There,

$\mathrm{i}=1,2,3, \ldots, \mathrm{n}$

$\mathrm{j}=1,2,3, \ldots, \mathrm{s}, \mathrm{s}>\mathrm{n}$

$\mathrm{x}_{\mathrm{ij}}=\mathrm{x}_{\mathrm{i}}\left(\mathrm{t}_{\mathrm{j}}\right)$ is the free response of the system of the $\mathrm{i}$-th measuring point in the $\mathrm{j}$ moment

$x_{i j}=x_{i}\left(t_{j}+\Delta t\right)$ is the free response of the system of the measuring point $\mathrm{i}$ in the delay time $\Delta \mathrm{t}$

Equation (4), (5) and (6) can be obtained according to the method of literature (Samir and Pappa, 1981):

$$
\hat{X}_{l}=A X_{l}
$$

where, in $\mathrm{A}=$ The system matrix

If measured in the different single excitation condition free response matrix is $\mathrm{X}_{1}, \mathrm{X}_{2}, \mathrm{X}_{3} \ldots \mathrm{X}_{\mathrm{m}}, \mathrm{m}$ is a single excitation response times, $\hat{X}_{1}, \hat{X}_{2}, \hat{X}_{3} \ldots \hat{X}_{\mathrm{m}}$ is the delay response matrix corresponding to $X_{1}, X_{2}$, $\mathrm{X}_{3} \ldots \mathrm{X}_{\mathrm{m}}$ matrix.

Taking into account the system matrix A does not vary with changes in the initial conditions change, therefore we can get:

$$
\left[\widehat{X}_{1}, \hat{X}_{2}, \widehat{X}_{3} \cdots \hat{X}_{m}\right]=A\left[X_{1}, X_{2}, X_{3} \cdots X_{m}\right]
$$

Order

$$
\begin{aligned}
& \hat{X}=\left[\hat{X}_{1}, \hat{X}_{2}, \hat{X}_{3} \cdots \hat{X}_{m}\right] \\
& X=\left[X_{1}, X_{2}, X_{3} \cdots X_{m}\right]
\end{aligned}
$$

Therefore,

$$
\widehat{X}=A X
$$

Equation (7) and (11) have same form, but the composition of the matrix of data are different. It is clear that the response data matrix $\hat{X}, \mathrm{X}$ have contains more information than $\hat{X}_{1}, X_{1}$. The result is bound to increase recognition accuracy nonvolatile mode.

Using singular value decomposition, the Generalized Inverse Solving Eq. (11) in the system matrix A. Finally, the identification problem become into an eigenvalue problem:

$$
A \phi_{r}=\mu_{r} \phi_{r},(r=1,2,3, \cdots 2 n)
$$

where,

$\emptyset_{\mathrm{r}}$ : The $\mathrm{r}^{\text {th }}$ order complex modal vector of the structure $\mu_{\mathrm{r}}$ : The $\mathrm{r}^{\text {th }}$ order complex eigenvalue

Assuming that the damping matrix $\mathrm{C}$ can be decoupled, according to the literature (Samir and Pappa, 1981), we can get: 


$$
\mu_{r}=e^{\lambda_{r} \Delta t}
$$

where,

$$
\lambda_{r}=-\xi_{r} \omega_{r}+i \omega_{r} \sqrt{1-\xi_{r}^{2}}
$$

$\omega_{\mathrm{r}}=$ The $\mathrm{r}^{\text {th }}$ order natural frequency

$\xi_{\mathrm{r}}=$ The $\mathrm{r}^{\text {th }}$ order modal damping ratio

Application of Eq. (12) and (13) can be solved the parameter $\omega_{\mathrm{r}}$ and $\xi_{\mathrm{r}}$.

It is noted that in the recognition, we use a virtual measuring point in order to constitute the over determined mathematical model, the overall mold state confidence factors OAMCF to distinguish true modal and noise mode, sometimes add some physical judgment, such as damping to over engineering common sense or negative damping can immediately conclude that the noise modal. There we set of three different levels of MCF (Huang, 1986):

The first level requirements:

$$
|M C F|>0.95,|\arg M C F|<10^{\circ}
$$

The second level requirements:

$$
|M C F|>0.80,|\arg M C F|<20^{\circ}
$$

The first third level requirements:

$$
|M C F|>0.60,|\arg M C F|<30^{\circ}
$$

We cannot identify if MCF below the third level. OAMCF is the proportion of value MCF reach above a certain level of total MCF.

Parallel subspace iteration method: Equation (11) is a Multi-input problem that is huge number degrees of freedom eigenvalue problem, the subspace iteration method is used to solve the Multi-input problem. The advantage of the subspace iteration method is that the first $\mathrm{N}$ eigenvalues and eigenvectors can be obtained and decided by the users. For a complicated eigenvalue problem with huge number degrees of freedom, this method could be efficient since the subspace iteration method only needed first several modes, such as 30 to 60 modes. The following paragraph shows the procedure of the subspace iteration method:

1. Consider a generalized eigenvalue problem as:

$$
\left(K-\omega^{2} M\right) \phi=0
$$

2. Assume an initial iteration matrix $X_{k}$

3. Iterate from subspace $X_{k}$ to $X_{k+1}$

$$
\begin{aligned}
& K X_{k+1}=M X_{k} \\
& \text { 4. } \mathrm{K}_{\mathrm{k}+1}=\mathrm{X}_{\mathrm{k}+1}^{\mathrm{T}} \mathrm{KX}_{\mathrm{k}+1}, \mathrm{M}_{\mathrm{k}+1}=\mathrm{X}_{\mathrm{k}+1}^{\mathrm{T}} \mathrm{MX}_{\mathrm{k}+1}
\end{aligned}
$$

5. Solve the characteristic equation

$$
K_{k+1} Q_{k+1}=M_{k+1} Q_{k+1} \Lambda_{k+1},
$$

where, the eigenvector $\mathrm{Q}_{\mathrm{k}+1}$ and the eigenvalue $\Lambda_{\mathrm{k}+1}$ can be determined by the Jacobi method

6. $\Lambda_{\mathrm{k}+1}=\mathrm{X}_{\mathrm{k}+1} \mathrm{Q}_{\mathrm{k}+1}$

7. Check $\Lambda_{\mathrm{k}+1}$ is convergent or not. If $\Lambda_{\mathrm{k}+1}$ does not have the convergence; do the iteration of $K_{k+1}$ for the next iteration at last step (4)

\section{NUMERICAL ANALYSIS OF QUJIANG BRIDGE}

Qujiang bridge model overview: The Qujiang bridge model of the finite element analysis will be discussed. The bridge is set to be a 3-span pre-stressed box girder bridge with the span length of $20 \mathrm{~m}$, in which simply supported girders are used. That is, the total length of the bridge is $60 \mathrm{~m}$.

The length of the bridge pier foundation is $5 \mathrm{~m}$ and the dimension of it is $3.5 \mathrm{~m}$. The diameter of the pile is $1.5 \mathrm{~m}$. There is a Reinforced Concrete (RC) cap on the top surfaces of the piles with a thickness of $3 \mathrm{~m}$, which is buried underground. The bridge section is shown in Fig. 1, which is $18 \mathrm{~m}$ on the top surface, $9 \mathrm{~m}$ on the bottom surface with the section depth of $1.9 \mathrm{~m}$. The Young's modulus of the bridge beams is $2.94 \times 107$ $\mathrm{kN} / \mathrm{m}^{2}$. The Young's modulus of the bridge piers, caps and piles is $2.45 \times 107 \mathrm{kN} / \mathrm{m}^{2}$. The total mass density and the Poisson's ratio of the whole bridge structure are $2.4 \mathrm{~T} / \mathrm{m}^{3}$ and 0.25 .

Introduction of study case: In this study, the varied bridge structure models constructed in this study will be used to discuss the relationship between the bridge natural frequency and the foundation scour depth. First, all the bridge superstructure property is assumed to be in the same condition, that is, the bridge superstructure is set to be the same for all the analysis meshes. In this study, it is assumed that the bridge superstructure does not have great impact on the relationship between the bridge natural frequency and the scour depth. Therefore, the only parameter considered in this study is that how the pile arrangement of type with the different scour depth have impact on the bridge natural frequency. Furthermore, each pile arrangement of type is divided into 5 different scour depths, which are 0,2 , 6,11 and $15 \mathrm{~m}$, respectively. The boundary condition of the soil layer is set to be rollers, that is, the normal deformation of the soil is defined.

Numerical model: The three-dimensional bridge pile foundation mesh of the case is shown in the Fig. 2. As mentioned above, all analyzed cases contain three 


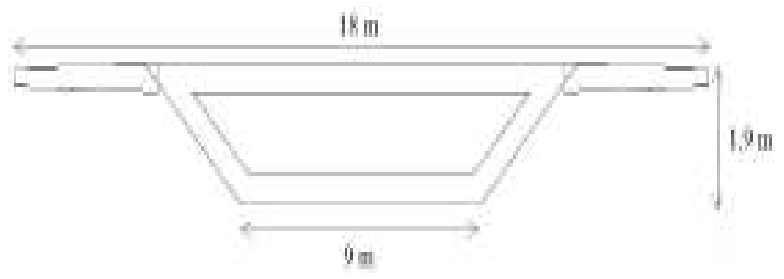

Fig. 1: The size of Qujiang bridge section
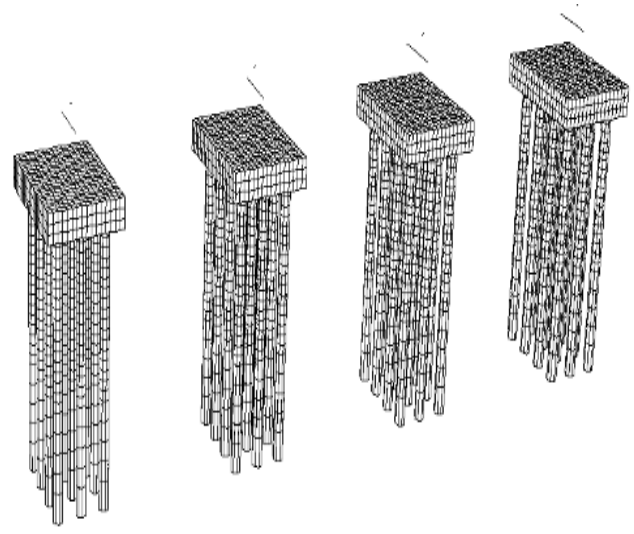

Fig. 2: The three-dimensional bridge pile foundation mesh

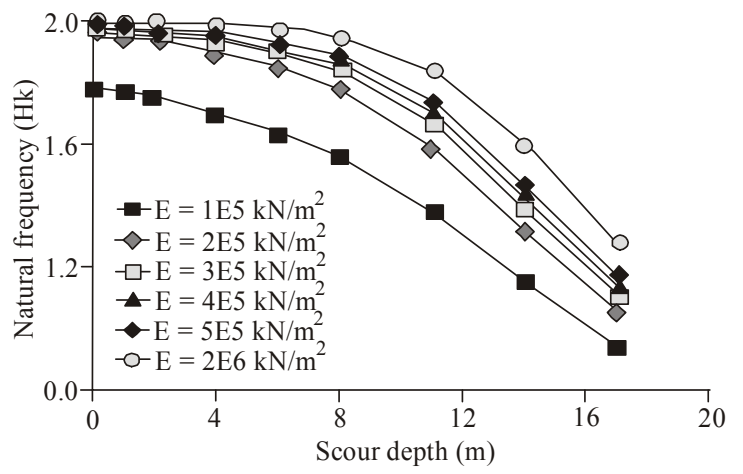

(a) Bridge pile length with $25 \mathrm{~m}$

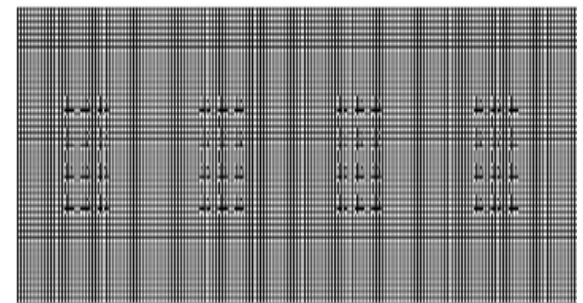

Fig. 3: The two-dimensional pile foundation mesh

different pile lengths, which are 25, 39 and $41 \mathrm{~m}$, respectively. Figure 3 shows the two-dimensional arrangement of the pile foundation mesh in the case. There are 12 piles in each pile cap and the formation is 3 piles in the $\mathrm{X}$ direction and 4 piles in the $\mathrm{Y}$ direction.

\section{THE COMPARISONS OF CALCULATION RESULTS}

In the load case, as in Fig. 4 show, the maximum value of the bridge natural frequency is $1.967 \mathrm{~Hz}$, which appears in the condition of pile length of $41 \mathrm{~m}$, soil Young's modulus of $2 \mathrm{E} 6 \mathrm{kN} / \mathrm{m}^{2}$ and the scour depth of $0 \mathrm{~m}$. The minimum value of the bridge natural

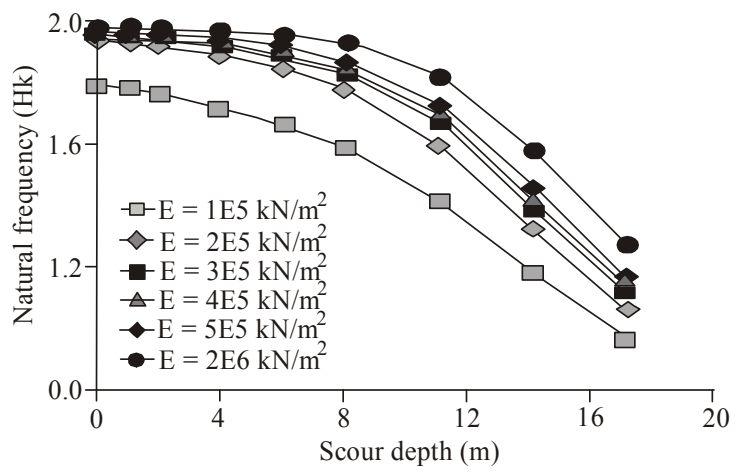

(b) Bridge pile length with $39 \mathrm{~m}$

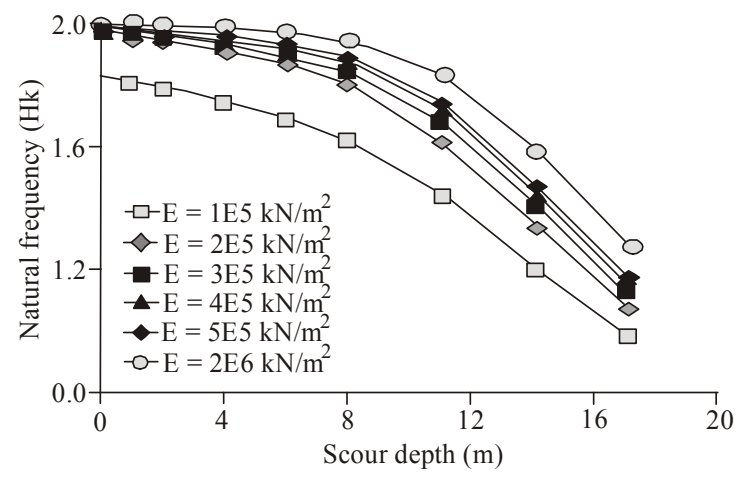

(c) Bridge pile length with $41 \mathrm{~m}$

Fig. 4: The relationship between the bridge natural frequency and the bridge foundation scour depth 


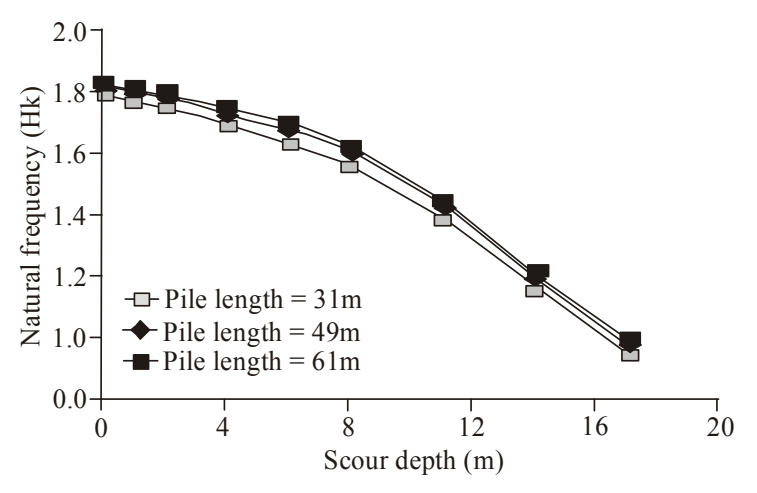

(a) Soil strength $\mathrm{E}=2 \mathrm{E} 5 \mathrm{kN} / \mathrm{m}^{2}$

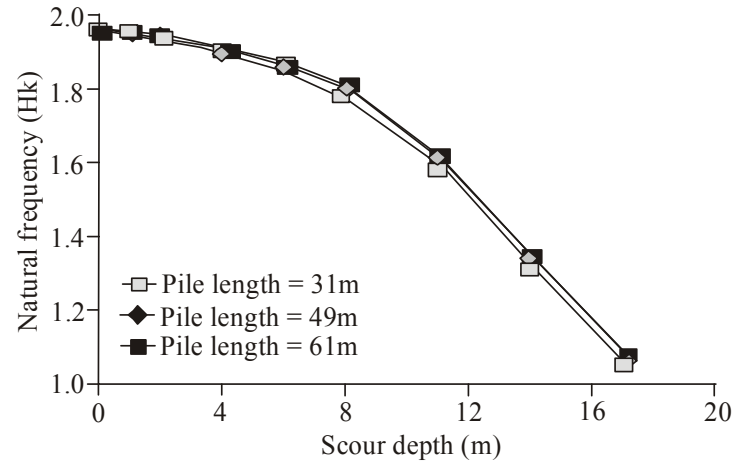

(b) Soil strength $\mathrm{E}=4 \mathrm{E} 5 \mathrm{kN} / \mathrm{m}^{2}$

Fig. 5: The relationship between the bridge natural frequency and the bridge foundation scour depth under the same soil strength

frequency is $0.9023 \mathrm{~Hz}$, which happens in the condition of pile length of $25 \mathrm{~m}$; soil Young's modulus of 1E5 $\mathrm{kN} / \mathrm{m}^{2}$ and the scour depth of $17 \mathrm{~m}$. The frequency difference is not obvious when the foundation scour depth does not exceed $6 \mathrm{~m}$. Figure 5 shows the relationship between the bridge natural frequency and the bridge foundation scour depth under the same soil strength.

\section{CONCLUSION}

- The different pile formation will cause different impact on the bridge natural frequency.

- If the pile is inserted to the high strength soil, the different lengths of pile would not have influence on the bridge natural frequency.

- If the soil is non-homogeneous, the frequencyscour depth relationship may have different looks.

\section{ACKNOWLEDGMENT}

This work was financially supported by Zhejiang Provincial Education Department's research projects, the project name: Synchronous Identification Method of Structural damage and load under ambient excitation, project number: Y201223039.

\section{REFERENCES}

Coleman, E., 2005. Clear water local scour at complex piers. J. Hydraul. Eng., ASCE, 131: 330-340.

Darghi, B., 1990. Controlling mechanism of local scouring. ASCE J. Hydraul. Eng., 116: 1197-1214.

De Falco, F. and R. Mele, 2002. The monitoring of bridges for scour by sonar and sedimentary. NDE E Int., 35: 117-123.

Dey, S., 1999. Time-variation of scour in the vicinity of circular piers. ASCE, Proceeding of the Institution of Civil Engineering-Water Maritime and Energy, 136: $67-75$.
Harger, W.H. and J. Unger, 2010. Bridge pier scour under flood waves [J]. ASCE, J. Hydraul. Eng., 136: 842-847.

Huang, S.L., 1986. Signal Processing of Engineering. People's Communications Press, Beijing, pp: 28-70.

Ji, B.H. and Z.Q. Fu, 2010. Analysis of Chinese beidge collase accident cause in recent years. China Civil Eng. J., 43(s1): 495-498.

Karami, H., A. Ardeshir, M. Saneie, S.A. Salamatian, 2012. Prediction of time variation of scour depth around spur dikes using neural networks. J. Hydroinformatics, 14(1): 180-191.

Lu, J.Y., Z.Z. Shi, J.H. Hong, J.H. Hong, J.J. Lee and R.V. Raikar, 2011. Temporal variation of scour depth at nonuniform cylindrical piers. ASCE, J. Hydraul. Eng., 137: 45-56.

Mattin-Vide, J.P., 1998. Local scour at piled bridge foundations. ASCE, J. Hydraul. Eng., 124: 439-444.

Melville, B.W. and A.J. Raudkivi, 1996. Effects of foundation geometry on bridge pier scour. ASCE, J. Hydraul. Eng., 122: 203-209.

Oliveto, G. and W.H. Harger, 2002. Temporal evolution of clear-water pier and abutment scour. ASCE, J. Hydraul. Eng., 128: 111-120.

Robertson, I.N., H.R. Riggs, S.C.S. Yim and Y.L. Young, 2007. Lessons from hurricane Katrina storm surge on bridges and building. ASCE, J. WaterwayPort Coast. Ocean Eng., 133(6): 463-466.

Samir, R.I. and R.S. Pappa, 1981.A parametric study of the "ITD" modal identification algorithm. Shock Vib. Bull., 51(3): 43-72.

Wardhaha, K. and F.C. Hadripriono, 2003. Analysis of recent bridge failure in the United States. ASCE, J. Perform. Constr. Facil., 17(3): 144-150. 